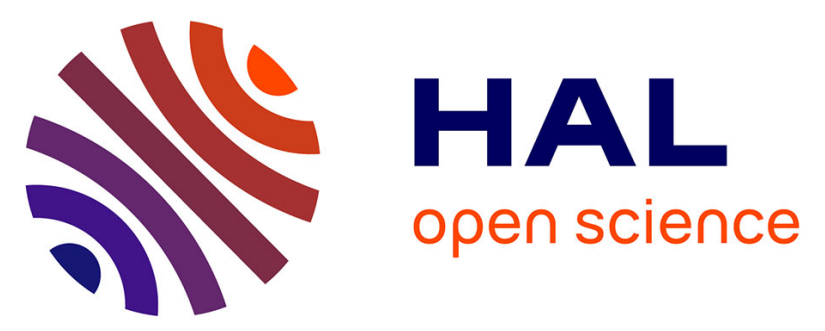

\title{
Stress analysis by Kossel microdiffraction on a nickel-based single crystal superalloy during an in situ tensile test - Comparison with classical X-Ray diffraction
}

Denis Bouscaud, Raphaël Pesci, Sophie Berveiller, Etienne Patoor

\section{To cite this version:}

Denis Bouscaud, Raphaël Pesci, Sophie Berveiller, Etienne Patoor. Stress analysis by Kossel microdiffraction on a nickel-based single crystal superalloy during an in situ tensile test - Comparison with classical X-Ray diffraction. Materials Science Forum, 2011, 681, pp.1-6. 10.4028/www.scientific.net/MSF.681.1 . hal-01213841

\section{HAL Id: hal-01213841 \\ https://hal.science/hal-01213841}

Submitted on 10 Jul 2018

HAL is a multi-disciplinary open access archive for the deposit and dissemination of scientific research documents, whether they are published or not. The documents may come from teaching and research institutions in France or abroad, or from public or private research centers.
L'archive ouverte pluridisciplinaire HAL, est destinée au dépôt et à la diffusion de documents scientifiques de niveau recherche, publiés ou non, émanant des établissements d'enseignement et de recherche français ou étrangers, des laboratoires publics ou privés. 


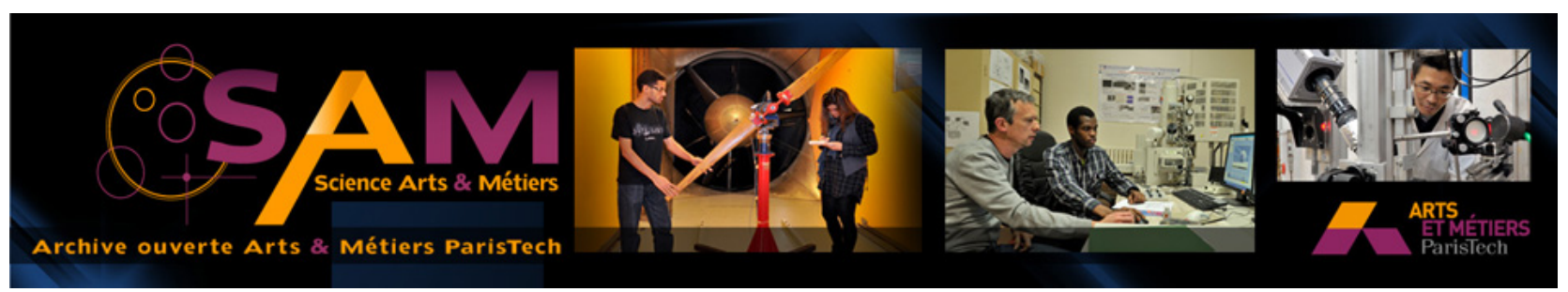

\section{Science Arts \& Métiers (SAM)}

is an open access repository that collects the work of Arts et Métiers ParisTech researchers and makes it freely available over the web where possible.

This is an author-deposited version published in: http://sam.ensam.eu

Handle ID: .http://hdl.handle.net/null

\section{To cite this version :}

Denis BOUSCAUD, Raphaël PESCI, Sophie BERVEILLER, Etienne PATOOR - Stress analysis by Kossel microdiffraction on a nickel-based single crystal superalloy during an in situ tensile test - Comparison with classical X-Ray diffraction - Stress analysis by Kossel microdiffraction on a nickel-based single crystal superalloy during an in situ tensile test - Comparison with classical XRay diffraction - Vol. 681, p.1-6 - 2011 


\title{
Stress analysis by Kossel microdiffraction on a nickel-based single crystal superalloy during an in situ tensile test - Comparison with classical X-Ray diffraction
}

\author{
Denis BOUSCAUD ${ }^{a}$, Raphaël PESCI ${ }^{\mathrm{b}}$, Sophie BERVEILLER ${ }^{\mathrm{c}}$, Etienne PATOOR ${ }^{\mathrm{d}}$ \\ LPMM FRE CNRS 3236 - Arts et Métiers ParisTech, 4 rue Augustin Fresnel, 57078 Metz, France \\ adenis.bouscaud@ensam.eu, ${ }^{b}$ raphael.pesci@ensam.eu, csophie.berveiller@ensam.eu, \\ detienne.patoor@ensam.eu
}

Keywords: Kossel microdiffraction, in situ, scanning electron microscope, synchrotron radiation.

\begin{abstract}
.
A Kossel microdiffraction experimental set up is under development inside a Scanning Electron Microscope (SEM) in order to determine the crystallographic orientation as well as the inter- and intragranular strains and stresses. An area of about one cubic micrometer can be analysed using the microscope probe, which enables to study different kinds of elements such as a grain boundary, a crack, a microelectronic component, etc. The diffraction pattern is recorded by a high resolution Charge-Coupled Device (CCD) camera. The crystallographic orientation, the lattice parameters and the elastic strain tensor of the probed area are deduced from the pattern indexation using a homemade software. The purpose of this paper is to report some results achieved up to now to estimate the reliability of the Kossel microdiffraction technique.
\end{abstract}

\section{Introduction}

Due to the growing complexity of new materials and their applications, it is increasingly necessary to know the strain and the stress state at a lower scale, a micrometer one, particularly in the case of micro- and nanosystems. Kossel microdiffraction is a tool that has been adapted for use in the Scanning Electron Microscopes (SEM), which enables to determine not only the crystallographic orientation, but also the inter- and intragranular strain and stress state while observing the microstructure and its possible evolution during in situ mechanical tests.

Different techniques are available to obtain residual stresses at the micrometer scale: for instance micro-Raman spectroscopy [1], X-Ray microdiffraction with a white synchrotron beam [2], convergent beam electron diffraction inside a transmission electron microscope [3]. Kossel microdiffraction is currently being developed because of some advantages comparing to these techniques [4]. Indeed, the use inside a SEM is easy, non destructive and can be applied to metallic components. Moreover, spatial and strain resolutions are competitive.

In the 1970s, Kossel microdiffraction was used for the determination of crystallographic orientations and lattice parameters $[5,6,7]$. Patterns were recorded on photographic films. In the 1990s, the development of high resolution CCD cameras began allowing easier and faster data collection. Lattice strain measurements finally began to be feasible [8].

The aim of this study is to check the reliability of the Kossel technique. Kossel line patterns on single crystals under loading have been recorded and the goal is to compare the stresses given by the technique with the stresses applied to the samples. We also compare results with those obtained by classical X-Ray Diffraction (XRD).

\section{Kossel technique}

In a SEM, when an electron beam is focused on a material, the latter is excited and thus an X-rays spherical wave is emitted. A part of these rays is diffracted by the crystallographic planes forming the so-called Kossel cones, in accordance with the Bragg's law: $\lambda=2 \mathrm{~d} \sin \theta(\lambda$ : wavelength of the 
excited element, d: interreticular length, $\theta$ : Bragg's angle). A CCD camera intercepts a part of these cones, which are all emitted at the same time (one diffraction cone for each (hkl) diffracting plane). Kossel conics (lines or complete circles) are calculated from the orientation of the cones and the distance between the sample and the screen (Fig. 1).

It is possible to excite the material with different types of radiation. Conventionally, an electron beam is used to excite either the sample directly or a target placed close to the sample [9]. This latter technique is called pseudo-Kossel. Kossel microdiffraction can also be obtained by employing synchrotron radiation [10].

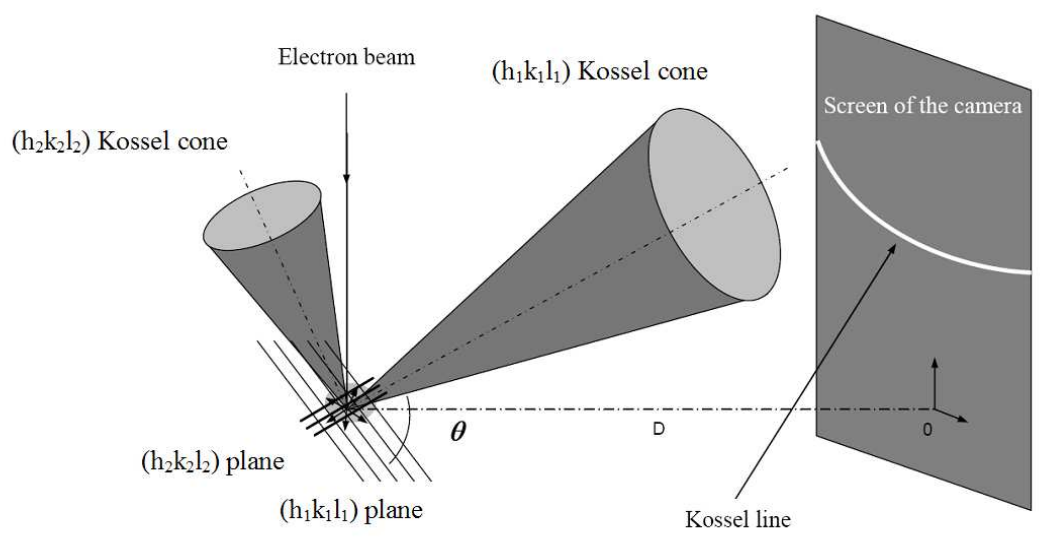

Fig. 1: The principle of the Kossel microdiffraction inside a SEM

Several materials have already been tested with this technique: copper, nickel and titanium alloys, steels and germanium. An example of a Kossel line pattern from a grain of interstitial free (IF) steel is shown in Fig. 2b. The grain that was selected is circled in Fig. 2a. The spatial resolution is estimated to be about $1 \mu \mathrm{m}^{3}$, for a $20 \mathrm{kV}$ microscope voltage.
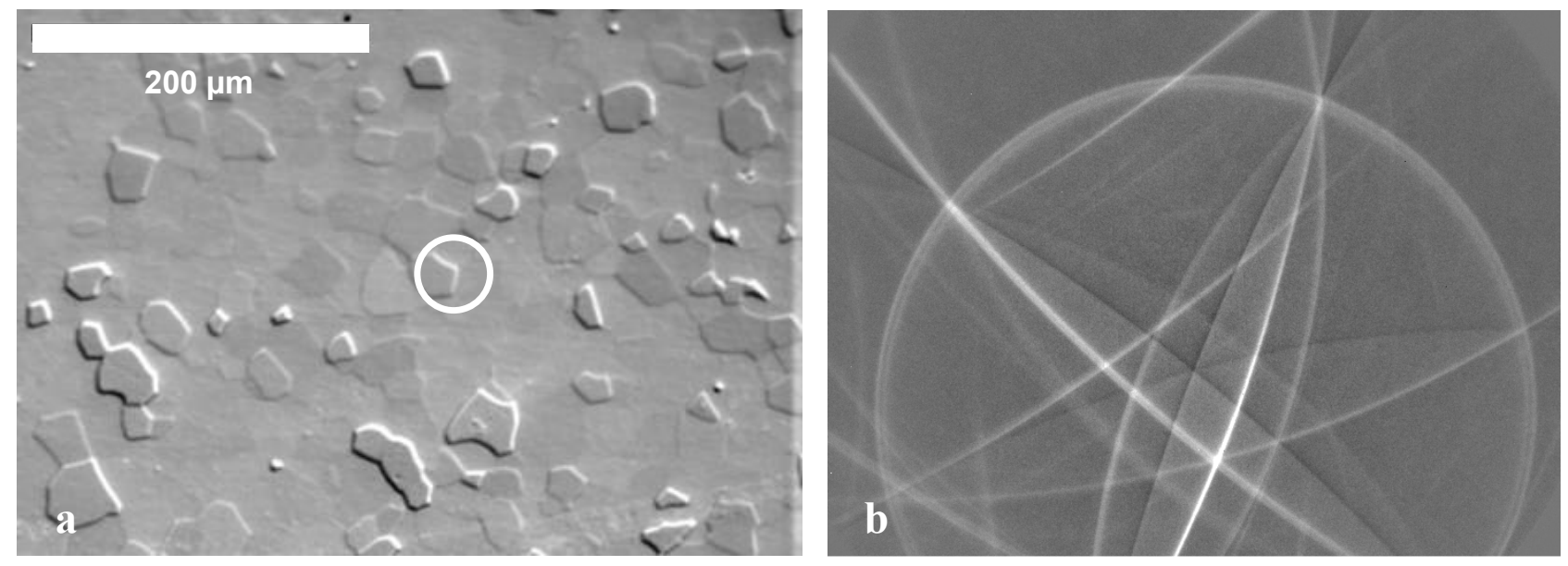

Fig. 2: a) SEM image of the microstructure showing the grain analysed by Kossel diffraction -

b) Experimental Kossel line pattern from an IF steel grain

The obtained Kossel line pattern is then indexed using a semi-automatic program, KSLStrain, developed by Adam Morawiec [11]. Several parameters are fulfilled in the program: the radiation wavelength of the emitted X-rays that is known with relatively high accuracy, the unit cell of the material, the pixel size of the camera and approximate values of the camera geometry parameters (sample-to-detector distance and the location of the pattern centre). Then, conics on the pattern are marked manually selecting a number of points per each Kossel line (Fig.3a). Starting with fixed reference values of lattice parameters, a procedure is used to find the geometry of the pattern. Once 
the crystal orientation is determined and the camera geometry parameters are tuned, the program can proceed with the refinement of lattice parameters. The program uses the so-called "K-line equation based scheme". Kossel conics manually marked by the operator are matched to corresponding conics in simulated patterns. At the end, the camera geometry parameters, the crystal orientation and the strain components are fitted together. Visual example of a result is shown in Fig.3b. The strain resolution is estimated to be about $3 \cdot 10^{-4}$ [11].
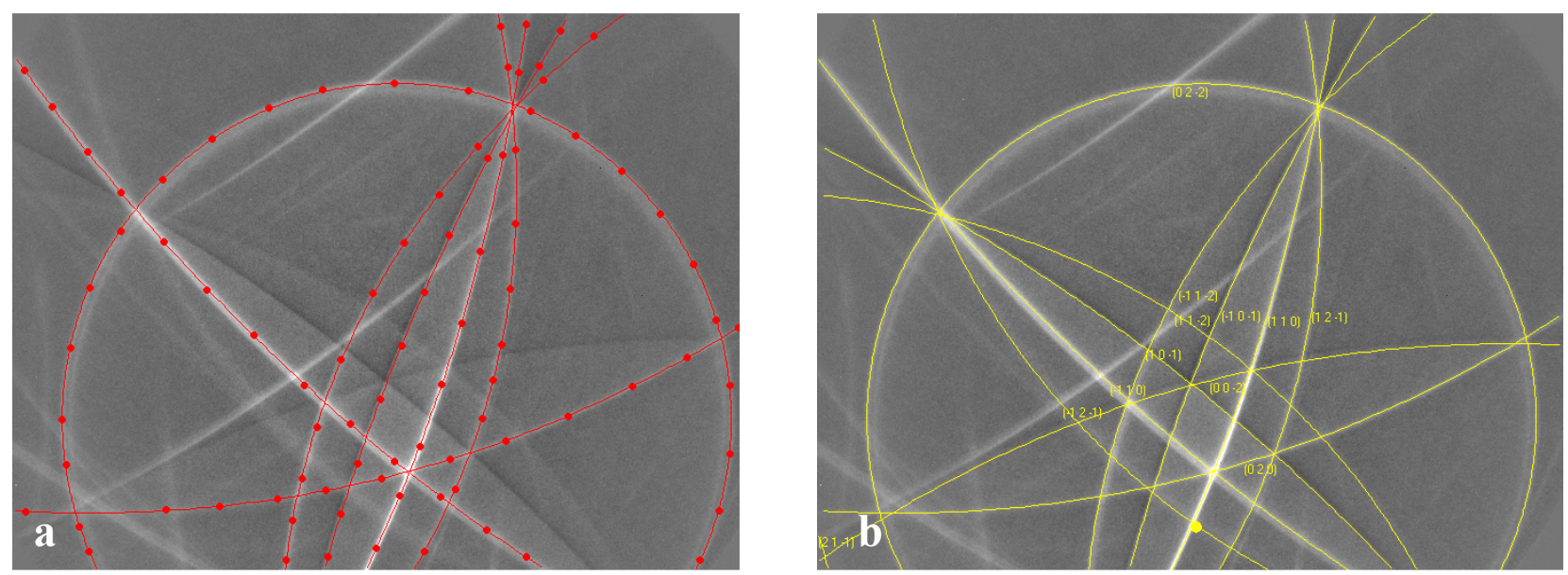

Fig. 3: a) IF steel pattern with some conics marked -

b) Simulated pattern after the fittings superimposed with the experimental pattern

\section{Measurements on single crystals under loading}

To check the consistency of the stress results given by the Kossel microdiffraction, we have performed measurements on a nickel-based single crystal superalloy during an in situ tensile test. The chemical composition (in weight \%) of the material is the following: Base $\mathrm{Ni}-8 \% \mathrm{Cr}-5 \% \mathrm{Co}$ $-8 \% \mathrm{~W}-2 \% \mathrm{Mo}-5 \% \mathrm{Al}-1.5 \% \mathrm{Ti}-6 \% \mathrm{Ta}$. Its main feature is a high yield strength (about $900 \mathrm{MPa})$. In fact, it is made of two coherent phases: a Ni matrix $\gamma$ and ((Ni, Co, Cr) 3 ( $\mathrm{Al}, \mathrm{Ti}, \mathrm{Ta})$ ) cubic precipitates $\gamma^{\prime}$ (Fig.4a). We used a small tensile testing device (Fig.4b) to apply loading to "dog bone" specimens up to about 700MPa.
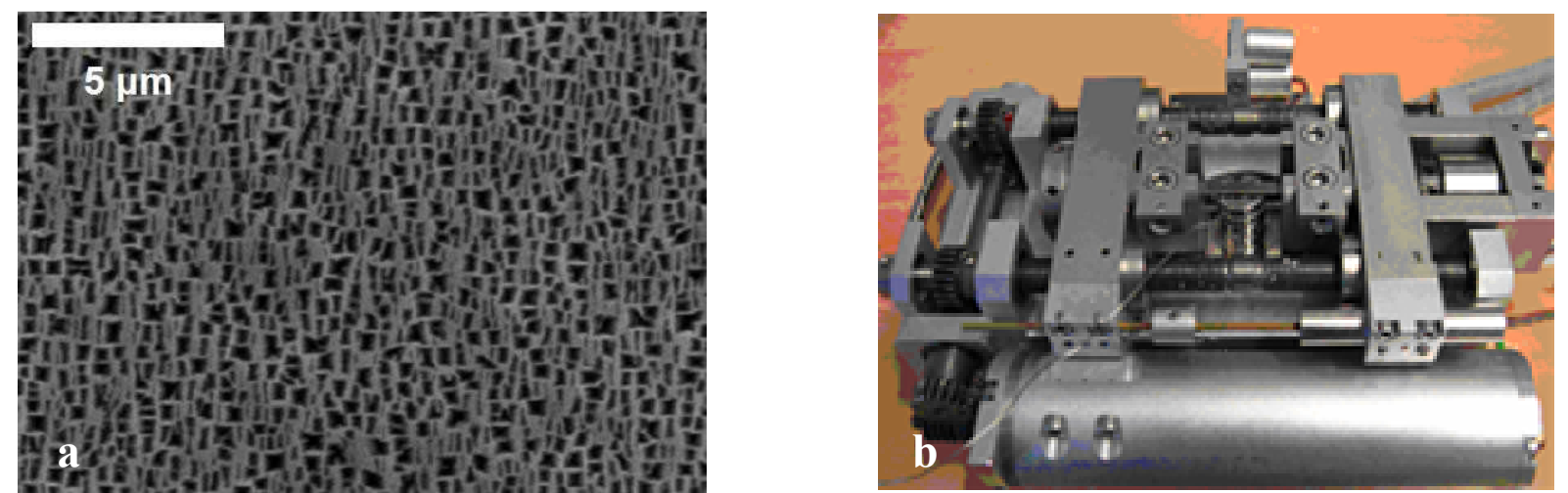

Fig. 4: a) SEM image of the nickel-based superalloy microstructure -

b) In situ uniaxial tensile/compressive testing device

Kossel experiments were performed by two different ways. First, a monochromatic synchrotron beam (European Synchrotron Radiation Facility, ID13 beamline, Fig.5a) was used to excite the material fluorescence. The beam size was about 3 micrometers. Photon energy of $9.4 \mathrm{keV}$ was chosen to be just above the K-edge of the nickel. Data was collected at different loadings and stress 
tensors were determined assuming a biaxial stress state, due to the low emission depth of X-rays (Fig.5b).

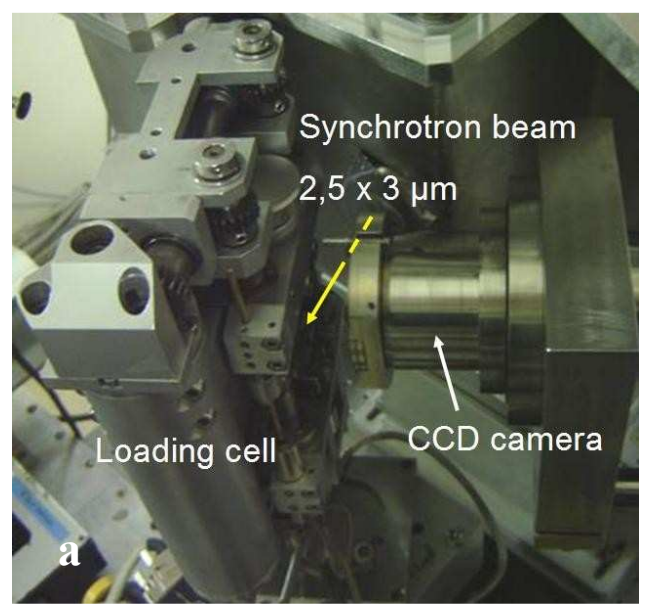

\begin{tabular}{|c|c|c|c|c|}
\hline \multicolumn{2}{|c|}{ Initial state } & 400MPa loading & 590MPa loading \\
\hline$\left(\begin{array}{ccc}10 & 55 & 0 \\
& -25 & 0 \\
& & 0\end{array}\right)$ & $\left(\begin{array}{ccc}400 & -10 & 0 \\
& -135 & 0 \\
& & 0\end{array}\right)$ & $\left(\begin{array}{ccc}500 & -20 & 0 \\
& -200 & 0 \\
& & 0\end{array}\right)$ \\
\hline
\end{tabular}

b

Fig.5: a) Experimental set up used at ID13 (ESRF) to obtain Kossel line patterns from a monochromatic synchrotron beam - b) Stress tensors (MPa) obtained by Kossel diffraction with a synchrotron beam at different stress states. $\sigma_{11}$ according to the tensile direction.

Assumption: biaxial stress sate.

The same experiments were performed inside the SEM. Results are shown in Table 1 and an example of a Kossel line pattern is shown in Fig.6.

Table 1: Stress tensors (in MPa) obtained by Kossel diffraction inside the SEM at different stress states. $\sigma_{11}$ according to the tensile direction. Assumption: biaxial stress sate.

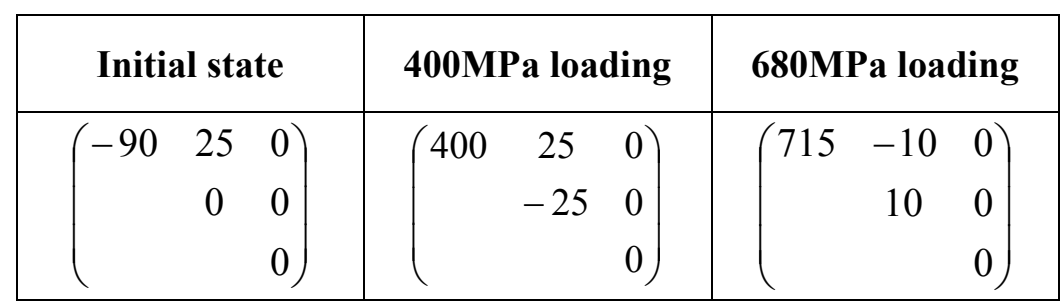

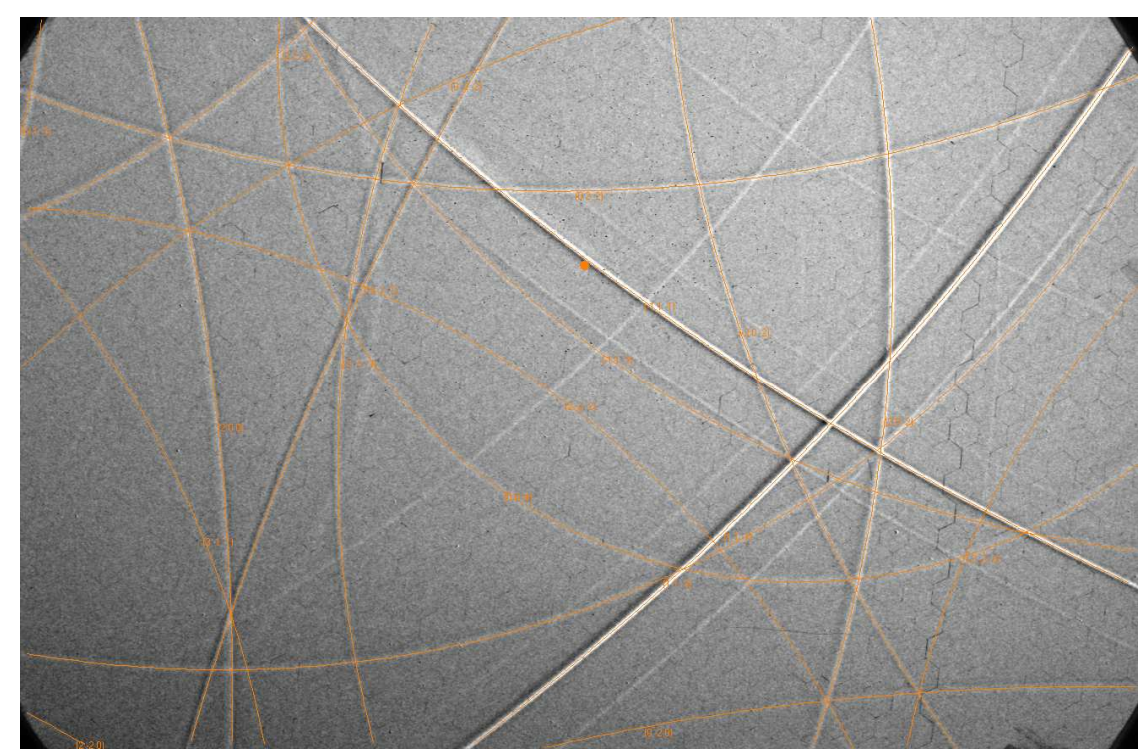

Fig.6: Simulated pattern after the fittings superimposed with the experimental one (400MPa loading) 
Single crystal XRD stress analyses, using the Ortner's method [12], were carried out within a fourcircle goniometer to compare with Kossel experiments (Table 2). The probed area was about a few $\mathrm{mm}^{2}$.

Table 2: Stress tensors (MPa) obtained by single crystal XRD.

$\sigma_{11}$ according to the tensile direction. Assumption: $\sigma_{33}=0$.

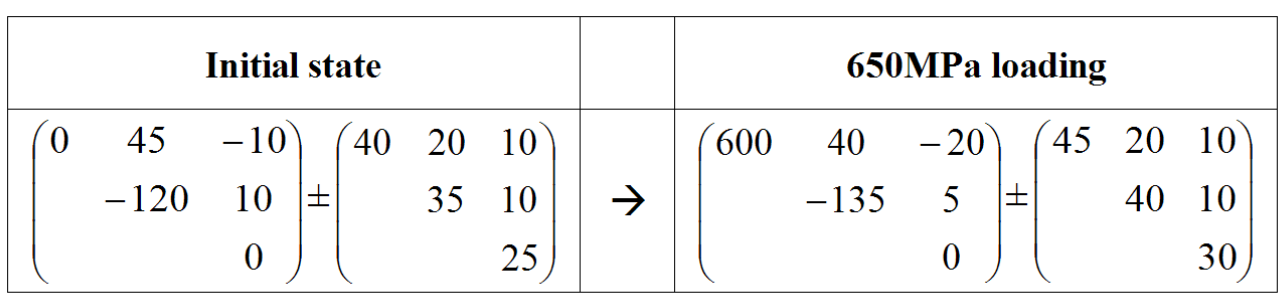

With the assumption of a biaxial stress state for the stress calculation from Kossel patterns, in situ stress results given by the three techniques and the macroscopic stress applied by the machine were compared, showing a good agreement.

XRD measurements in one grain take several hours, so a slight relaxation of the tensile device can explain why the $\sigma_{11}$ obtained is a little below the applied stress. The $\sigma_{22}$ compressive values, which are the same for the two loadings, are probably due to the surface preparation.

In synchrotron experiments, only one Kossel line pattern was obtained per loading. The synchrotron beam was focused at a random location on the single crystal surface. On the other hand, in the SEM, three patterns were recorded per loading and stress tensors shown in Table 1 correspond to an average of three measurements. Three electronic spot locations were chosen a few hundreds of micrometers apart. The results are consistent with the loading applied but we noticed high standard deviations. The $\sigma_{11}$ deviations are shown in Table 3. For the initial state, the non-uniform surface preparation could explain these deviations. Once the material is loaded, the standard deviations decrease.

Table 3: $\sigma_{11}$ standard deviations $\left(\Delta \sigma_{11}\right)$ calculated from three different Kossel analyses.

\begin{tabular}{|c|c|c|c|}
\cline { 2 - 4 } \multicolumn{1}{c|}{} & Initial state & 400MPa loading & 680MPa loading \\
\hline$\Delta \sigma_{11}[\mathrm{MPa}]$ & 135 & 75 & 70 \\
\hline
\end{tabular}

These deviations are probably due to the stress distribution between the two phases, the lattice misfit or local deviations of residual stresses induced by the surface preparation. The last value (about 70MPa) can also give information about the stress resolution of the Kossel microdiffraction, when such a pattern as shown in Fig. 6 is obtained.

\section{Conclusion}

This paper reports on microscale stress measurements using a non-destructive method, Kossel microdiffraction. Kossel patterns were obtained during in situ tensile experiments on single crystals in the Scanning Electron Microscope and with a monochromatic synchrotron beam. The patterns, recorded by a high resolution $\mathrm{CCD}$ camera, contained enough lines to determine the crystallographic orientation of the crystal and the elastic deformation of the lattice. Nickel-based single crystal superalloys were analyzed: different loadings up to $700 \mathrm{MPa}$ were applied on these specimens with a tensile micromachine and compared with the values obtained using the Kossel technique. A good agreement was observed. The results show how Kossel microdiffraction can be used as a precise tool to obtain residual stresses in polycrystalline samples. This technique could be 
used, for example, to analyse residual stresses in microelectronic components like $\mathrm{Cu}-\mathrm{MEMS}$ (Micro Electro Mechanical Systems).

\section{References}

[1] I. De Wolf, M. Ignat, G. Pozza, L. Maniguet and H.E. Maes: Journal of Applied Physics, Vol. 82 (1999), p. 6477

[2] N. Tamura, H.A. Padmore and J.R. Patel: Materials Science and Engineering A399 (2005), p. 92

[3] S. Krämer, J. Mayer, C. Witt., A. Weickenmeier and M. Rühle: Ultramicroscopy, Vol. 81 (2000), p. 245

[4] S. Berveiller, P. Dubos, K. Inal, A. Eberhardt and E. Patoor: Materials Science Forum Vol. 490491 (2005), p. 159

[5] K. Lonsdale: Phil. Trans. A240 (1947), p. 219

[6] R. Tixier and C. Waché: Journal of Applied Crystallography 3 (1970), p. 466

[7] D. J. Dingley: Scanning 1 (1978), p. 79

[8] J. Bauch, St. Wege, M. Böhling and H.-J. Ullrich: Crystal Research and Technology 39(7) (2004), p. 623

[9] E. Langer, S. Däbritz, A. Röder and W. Hauffe: Journal of Analytical Chemistry 365 (1999), p. 212

[10]H.J. Ullrich and co-workers: Nuclear Instruments and Methods A349 (1994), p. 269

[11]A. Morawiec, R. Pesci, J.S. Lecomte: Ceramic Transactions, Vol. 201 (2008), p.163

[12] B. Ortner, Journal of Applied Crystallography, Vol. 22 (1989), p. 216 